\title{
A ÉTICA DA RESPONSABILIDADE EM ARENDT E JONAS
}

\author{
Sônia Maria Schio \\ Universidade Federal de Pelotas
}

\begin{abstract}
Hannah Arendt and Hans Jonas devised the "ethics of Responsibility". For Arendt ethics aims at politics, and for Jonas, at the future. Arendt believes that politics should think and organize the present in search of the future. Jonas relates ethics to politics, but he doesn't focus his discussion on this theme. Thus, it is questionable whether the two ethics preach the same content, or whether they diverge, and if so, in which content and at which moment. Furthermore, the new concepts that Arendt and Jonas add to ethical thinking, particularly what each one specifically brings about that makes their concepts both current and relevant .
\end{abstract}

Keywords: Ethics, responsibility, politics, Arendt, Jonas.

Resumo: Hannah Arendt e Hans Jonas conceberam uma ética que se denomina de "ética da responsabilidade". A ética, em Arendt, visa à política, e em Jonas, o futuro. Arendt entende que cabe à política pensar e organizar o presente visando ao futuro. Em Jonas, a ética relaciona-se com a política, mas ele não centraliza sua discussão nela. Assim, pode-se questionar se as duas éticas apregoam um mesmo conteúdo, ou se divergem, e, em ambos os casos, em quais conteúdos e momentos. E ainda, o que Arendt e Jonas agregam de novo ao pensamento ético, e em especial, o que cada um aporta de específico que torna suas concepções tanto atuais quanto relevantes.

Palavras-chave: Ética, responsabilidade, política, Arendt, Jonas.

Ambos os autores, Arendt e Jonas, apresentam muitos aspectos em comum: se conheceram ainda na Alemanha pré-hitlerista, foram alunos e pessoas próximas a Heiddeger e embasaram suas concepções no pensamento kantiano. Além disso, eles pensaram uma ética que cobria vários propósitos: não permitir que fatos como os vivenciados no Nazismo e nos demais 
Regimes Totalitários, que ambos vivenciaram, voltassem a ocorrer. Outro, o de que cada ser humano pudesse se tornar um cidadão preocupado com o que pensa e faz, responsabilizando-se, e que se inquietasse com o futuro que está sendo elaborado. Por fim, a apreensão com as obras humanas, especificamente com a tecnologia e suas possíveis consequências negativas para a Humanidade, especialmente a futura.

Com o objetivo de apresentar algumas semelhanças, mas especialmente as diferenças presentes no pensamento dos dois autores, mesmo que de forma sintética, é necessário retomar alguns pontos fundamentais do pensamento de cada um. Jonas (1903-1993) possui um conjunto de conhecimentos da biologia, os quais embasam várias reflexões. Ainda nesse viés, há os conteúdos da economia e da política. Arendt permanece com seu foco na política, com suas reflexões ancoradas na reflexão filosófica. Ambos possuem um acurado senso humanitário, e sua preocupação com a ética, com o mundo, com os seres humanos e nãohumanos é sincera, não caindo em questionamentos vazios ou em discursos meramente retóricos.

Pode-se iniciar citando quais são as noções, as questões, os termos, que mais aparecem e que apontam para os principais assuntos abordados pelos autores com relação aos temas éticos. Nesse sentido, um tópico recorrente é o da "ação humana", pois são as ações dos próprios seres humanos que possibilitaram os avanços tecnológicos (outro assunto em pauta), assim como as conseqüências (éticas) que essas atitudes geram, e que nem sempre visam ao benefício dos seres que habitam o planeta. Apesar disso, os aperfeiçoamentos, seja no conhecimento seja na técnica ou na qualidade de vida, precisam ser estendidos para todos, de forma refletida e séria. A apreensão com relação ao futuro também está no centro de suas exposições, pois é essa dimensão temporal que está com o perigo de se tornar impossível para os seres humanos e para algumas espécies animais e vegetais.

Quando Jonas questiona o conceito e a imagem de homem (2006, p. 21), ele pensa em uma "ética do respeito". Esse respeito se dirige aos outros seres, animados ou não ${ }^{1}$. Sem esse, segundo ele, não se pode fundamentar qualquer teoria que se pretenda como "ética". Para ele, é a partir da concepção de homem que se tem que se pode projetar o futuro. Em outros

1 Em Jonas, a "nova" ética engloba a natureza (Cf. BINGEMER apud JONAS, 2006, p. 18). 
termos, pode-se pensar em um ser que vive o "aqui e agora", aproveitando ao máximo tudo o que lhe é possível, e sem qualquer questionamento, que ele não esteja apto para viver no mundo, entre homens e coisas que são essenciais, pois egoisticamente está "fechado" para a alteridade e para o futuro. Talvez isso, em épocas passadas, não representasse algo "mau", pois as consequências de tais atitudes não portavam as mesmas possibilidades de tornar o futuro impróprio para os seres vivos.

A ética, por ele concebida é uma "ética da simultaneidade" (JONAS, 2006, p. 45), pois as atitudes de hoje devem considerar o presente e o futuro ao mesmo tempo (idem, 2006, p. 55). Nos termos do autor (idem, 2006, p. 49), os "efeitos finais para a continuidade da atividade humana no futuro" precisam estar na pauta atual, seja individual, seja coletivamente. Ou seja, a preocupação com o futuro não pode ser uma simples hipótese, pois deve tornar-se uma questão "produtiva" no sentido de gerar ações que objetivem a preservá-lo, ou possuindo "a característica de universalidade na medida real de sua eficácia” (idem, 2006, p. 49). Nesse contexto, pode-se questionar como esse "todo coletivo", que tem suas ações que se juntam, se unem, formando um conjunto, um todo quase indiscernível, pode se tornar "eficaz" sem que haja uma vontade que norteie as ações para que elas não continuem a degradar o meio, e que, ao contrário, o recuperem e o preservem para o futuro. Em outras palavras, como levar a, ou obrigar, cada cidadão (e também o Estado), a respeitar os acordos com relação às limitações da tecnologia, da agressão ao próprio homem e ao meio ambiente, não se escondendo sob o grupo? ${ }^{3}$

Em Jonas há uma forte ênfase no conceito de "dever", assim como nos resultados da tecnologia, mais do que em Arendt, e com uma crítica mais clara e contundente ao Sistema Capitalista e de sua forma de atuação que não leva em consideração a vida, seja das pessoas, dos animais ou do meio ambiente. Ele critica, também, a Teoria marxista (cf. JONAS, 2006, p. 22) que, na busca de aprimorar a vida humana, ampliou a exploração do homem

\footnotetext{
2 Segundo Jonas (2006, p. 86), "no processo decisório deve-se conceder preferência aos prognósticos de desastre em face dos prognósticos de felicidade. (...) a existência ou a essência do homem, em sua totalidade, nunca podem ser transformadas em apostas do agir".

${ }^{3}$ Kant com o "mentir a si mesmo" (em especial na obra A religião nos limites da simples razão) e Arendt, em vários artigos sobre como obter obediência sem violência (por exemplo, no texto "Que é autoridade?", na obra Entre o Passado e o Futuro).
} 
e do meio, somando-se a isso, após a Segunda Guerra Mundial, o perigo nuclear. A temática nuclear, que também aparece no pensamento de Arendt, torna-se mais marginal na de Jonas, mas não desaparece. E ela ainda está presente, pois, em 2010, por exemplo, mesmo que a bipolarização entre os Estados Unidos e a (ex-)União Soviética tenha desaparecido, outras nações a colocam em pauta, o Irã e a Coréia do Norte, em especial.

Ainda quando se afirma que Jonas é kantiano, tal relação é mais sensível do que em Arendt, apesar dela citá-lo constantemente. Ou melhor, o "Kant da moral" está presente em Jonas, tanto quando ele utiliza largamente o verbo "dever", quando reelabora o "imperativo categórico"4 para abarcar o futuro e a integridade do habitat terrestre. A relação saber-dever (cf. JONAS, 2006, p. 41) demonstra que há a necessidade de uma nova forma de equacionar o saber, não mais com a técnica, com o uso, com a utilidade, mas com aquilo que é necessário para manter a integridade, seja do planeta, seja de seus habitantes humanos e não-humanos. "A tecnologia assume um significado ético por causa do lugar central que ela agora ocupa subjetivamente nos fins da vida humana”, escreveu Jonas (2006, p. 43), na qual há um ator coletivo e um ato também coletivo. Aqui podem surgir diversos questionamentos.

Uma dessas perguntas pode direcionar-se à aparente supervalorização do conhecimento humano. Apesar desses saberes serem aplicados e causarem benefícios e prejuízos, no segundo caso eles poderiam também resolver os problemas gerados por seus produtos. Além disso, tais artefatos se tornaram essenciais para a vida humana, entende Arendt (1991, p. 160, por exemplo). Para ela, qualquer artefato que o homem elabora, passa a fazer parte de seu mundo, e ele passa a necessitar desses objetos como se esses sempre tivessem existido. E exemplos disso não nos faltam (eletricidade, celular, máquina de lavar, para citar poucos exemplos). A pergunta, então, seria sobre se há interesse em diminuir o ritmo de crescimento e de degradação do meio em prol da recuperação do ar, dos rios, das matas, entre outros. Certamente o saber aplicado é imprescindível, mas há indícios de uma real e autêntica "vontade" de deter os problemas que a tecnologia criou? A resposta parece ser

\footnotetext{
${ }^{4} \mathrm{O}$ imperativo categórico joniano é exposto da seguinte forma: "Aja de modo a que os efeitos de tua ação sejam compatíveis com a permanência de uma autêntica vida humana sobre a Terra" (JONAS, 2006, p. 47).
} 
negativa, pois há poucos seres humanos, na atualidade, que pretendem conter seu consumo, sua produção de lixo, por exemplo, para melhorar a situação ambiental. Novamente poucos se dispõem a "abrir mão" das benesses e das comodidades da vida hodierna. Certamente não é isso que Jonas espera das pessoas. Mas pode-se pensar que é possível "frear" certos excessos atuais, o que também auxiliaria a reduzir, se não é possível evitar, os problemas para o futuro.

A outra questão cabível relaciona-se com a possibilidade de responsabilizar esse "agente coletivo", assim como se pode pensar em apregoar uma "culpa coletiva" por certos acontecimentos 5 . Se as ações e a responsabilização são pessoais, como se poderia afirmar, em ética, que elas são coletivas? Arendt, quando trata da questão da culpabilidade e da responsabilização tem em mente que em uma sociedade de massa há o "domínio de ninguém", pois no momento em que "todos" são culpados, "ninguém" o é6. Nesse sentido há inclusive a possibilidade de afirmar que a moralidade é coletiva, social e histórica, mas não a eticidade. O que significa, em Jonas (2006, p. 44), que "a moralidade deve invadir a esfera do produzir"? Tal não deveria ser a tarefa da ética?

A crítica que ele faz ao "utopismo" (idem, 2006, p. 23), ao conceito de progresso que a Modernidade inaugurou e que povoa o imaginário da maioria das pessoas, porém de forma acrítica, precisa ser melhor explicitado e compreendido. Isto é, ele demonstra que a História da Humanidade não ocorre como o desenvolvimento de uma criança (o mesmo não se pode afirmar com relação ao cuidado que o mundo e o bebê carecem), isto é, em fases sucessivas e progressivas. Ele o demonstra distinguindo a cidade dos antigos e a vida atual, que ampliou os horizontes geográficos, diminuindo o natural, o que evidencia a necessidade de uma ética não mais tradicional: pois, se houve mudança, então é necessário adaptar-se (cf. JONAS, 2006, p. 33-34). Antes, o alcance da ação também era pequeno; hoje, não o é mais: os mandamentos e máximas da ética tradicional podiam ser mais reduzidos (idem, 2006, p. 36), o que hoje, com a Globalização, não mais se sustenta. Agora é preciso acrescentar "a natureza como responsabilidade humana"

\footnotetext{
${ }^{5}$ Arendt se questionou sobre a culpa do povo alemão com relação ao Nazismo em "Culpa organizada e responsabilidade coletiva", na obra Compreender (2008, p. 150-161).

${ }^{6}$ Como citou Arendt ao relatar o "Caso Eichmann", na obra Eichmann em Jerusalém.
} 
(idem, 2006, p. 39). Ou melhor: é até necessário alterar o conceito de ética: de homem-homem (antropocêntrica - cf. JONAS, 2006, p. 35), para uma ética homem-mundo (antropológica).

Jonas também introduz conceitos que normalmente não são da ética com o objetivo de que ela se torne mais humana. Por exemplo, o princípio de responsabilidade obriga ao "temor" e ao "respeito" (idem, 2006, p. 23). Aparecem também os de gratidão, de piedade, de humildade (idem, 2006, p. 84) e o de culpa. Quanto ao conceito de "cuidado", ele o utiliza, direcionando-o ao mundo, e sendo similar àquele dos pais para com os filhos pequenos. Quanto à sabedoria em detrimento ao conhecimento, segundo ele (idem, 2006, p. 63), a época atual exige escolhas com sabedoria. Porém, hoje não se acredita mais na sabedoria, um saber amplo e abrangente, não apenas racional, mas também afetivo, emocional, que envolva tanto os sentimentos como a sensibilidade, que alguns têm denominado de compaixão. Para ele, é preciso uma nova espécie de humanidade, mas como obtê-la a partir dos seres humanos que existem nesse momento? E as pessoas de hoje se sentem com a possibilidade de fazer escolhas sobre a produção, as tecnologias, entre outros temas? Ao que parece, as pessoas atuais se sentem presos a uma "engrenagem social" que lhes confere pouca ou nenhuma possibilidade de escolha, e pequena de ação. A ação individual tende a se perder em um "mar gigantesco" que arrasta e impossibilita qualquer opção individual que não siga a maioria, a massa. Além disso, há diversas organizações que buscam mostrar os problemas, juntamente às possibilidades de solução, inclusive atuando na "contramão" do normal. Eles, porém, parecem ser "profetas a clamar no deserto".

Em uma perspectiva Iluminista, é a "ética que deve instruir o autocontrole”, acredita Jonas (idem, p. 41 e também na p. 44), pois há uma "natureza modificada do agir humano", isto é, desapareceu a diferença entre o natural e o artificial. Mas isso modificou a natureza humana ou a condição humana? ${ }^{7}$ Nesse sentido, seria importante para o ser humano voltar a sentir que ele tem a possibilidade de ser um sujeito autônomo, de gerir a própria vida e as próprias atitudes. Porém, a massificação o torna incapaz de decidir e

\footnotetext{
${ }^{7}$ Para Arendt, natureza e condição humana são diferentes. A primeira trata do que é comum ao homem enquanto ser biológico; a segunda, enquanto humano. Por exemplo, devido a condição de "pluralidade", na qual todos compartilham o mesmo planeta, por isso sempre terão assuntos de interesse comum, porque sempre viverão juntos: no mesmo espaço geográfico que é a Terra.
} 
de agir, ou mesmo de perceber se tais são possíveis ou não. Também se pode perguntar, nesse viés, se ele ainda consegue se sentir responsável, ou se sente sua responsabilização diluir-se em um todo maior que o engloba e até o sufoca.

A ética, em Jonas (idem, 2006, p. 65-66), é possível "porque os homens agem, e a ética existe para ordenar suas ações e regular seu poder de agir”, assim "a ética entra em cena como regulação desse agir”. Ela trata das "capacidades de ação de um novo tipo, e exigem novas regras da ética", entende ele (idem, 2006, p. 66). Para Jonas, então, não há neutralidade em ética. E a ética precisa aplicar-se ao agir individual, assim como ao público, pois há imperativos, e um deles é: "deve haver de qualquer maneira um futuro" (JONAS, 2006, p. 69). O primeiro imperativo, entretanto, é o que expressa que deve existir uma humanidade (idem, 2006, p. 93). Adiantando novamente a discussão, em Arendt não há imperativos. Aliás, uma crítica que é dirigida a ela é a de ter, voluntariamente, desconsiderado a Crítica da Razão Prática de Kant, preferindo passar da Crítica da razão pura para a Crítica da faculdade de julgar.

A questão do mal também aparece nos dois autores. Em Jonas, porém, ele tem um cunho ontológico ${ }^{8}$, ausente em Arendt, que lhe confere uma conotação política: a "banalidade do mal". Para Jonas pode-se utilizar o medo do mal possível (idem, 2006, p. 71), pois "o mal nos impõe a sua simples presença”, havendo uma "heurística do medo", pois "o que deve ser temido ainda não foi experimentado” (idem, 2006, p. 72). Em outra perspectiva, em ambos a imaginação recebe um importante papel. Em Jonas, a "reflexão sobre o possível, plenamente desenvolvida na imaginação, oferece o acesso à nova verdade" (idem, 2006, p. 74) que é ideal. Ou seja, ao tratar do futuro, que é ideal, a imaginação o antecipa. Além disso, quando Jonas confere a esses "homens do futuro" uma espécie de "simultaneidade fictícia" (idem, 2006, p. 93), a imaginação se faz novamente presente. Em Arendt, a imaginação presentifica o que está ausente, pois a "coisa" ausente pertence ao mundo externo ou interno, e ao passado, mesmo que próximo, e a imaginação a torna presente ao mundo interno, em representação, permitindo que ocorra o pensar e o julgar (e nesse caso, também, o "pensar

${ }^{8}$ A ontologia, em Jonas, aparece como um "dever primário com o ser" (2006, p. 87). 
alargado" , pois a imaginação permite que os outros seres humanos possam ser levados em consideração, mesmo que eles não estejam presentes).

Com relação às expectativas para o futuro, Jonas apregoa que é mais prudente que se prefiram as piores expectativas: "a aceleração do desenvolvimento alimentado tecnologicamente nos reduz o tempo para autocorreções” (idem, 2006, p. 78), apesar do interesse, da inclinação e da opinião tenderem e poderem escolher o prognóstico mais propício. No entanto, tais pensamentos e atitudes podem levar à impossibilidade de reverter a situação ("pode ser tarde demais"). Há, ainda segundo ele, mais possibilidade da "profecia da desgraça" (idem, 2006, p. 77 e 83) ser mais adequada à situação. E se a tomada de consciência demorar, os prejuízos tornam-se cada vez mais difíceis de serem revertidos, e a liberdade para fazê-lo será cada vez menor (idem, 2006, p. 79).

O trato de Jonas para com a questão do tempo também precisa ser ressaltado. Para ele, o futuro tem preponderância tanto em relação ao presente como ao futuro, por exemplo, na p. 85: "para o bem do futuro, se aposta o próprio futuro”. Como o Prof. Rohbeck expôs em sua conferência (no I Colóquio Hans Jonas, em Pelotas), a historicidade não pode ser esquecida ou deslocada de lugar: o presente tem suas raízes no passado. Além disso, o presente é o tempo para se decidir e agir. Ambos, passado e presente são imprescindíveis se o objetivo é pensar no futuro. Em outra perspectiva, e Jonas, nesse sentido concorda com Arendt, houve uma "ruptura" no século XX, iniciada na Modernidade (séc. XVII), na qual o passado deixou de "lançar luzes" sobre o presente e o futuro, pois sua relevância foi questionada tão duramente a ponto de parecer que ele nada tem a oferecer, tanto ao presente quanto ao futuro, o que é um engano, pois essa situação deixa o humano "às cegas" no momento de agir. O passado possui o legado, com seus conhecimentos, regras, hábitos, exemplos, entre outros, que o ser humano necessita no momento de pensar, de julgar e de agir. Arendt, baseada em Kant, com relação aos juízos determinantes e reflexionantes (expostos na Crítica da faculdade de julgar), entende-os como fundamentais para o ser humano guiar-se na vida cotidiana, seja em momentos de normalidade, seja nos de exceção.

90 pensamento arendtiano, nesse sentido, está em consonância com o pensamento de Kant expresso na Crítica da faculdade de julgar, no parágrafo 40. 
Com a responsabilidade Joniana, a prudência torna-se o cerne do agir moral (cf. idem, 2006, p. 88). Essa prudência é uma cautela no momento de agir, é um saber básico que considera os resultados na ação. Tanto que ele afirma (idem, 2006, p. 93) que "tal é o nosso dever [de buscar e de ser uma humanidade verdadeira - cf. 2006, p. 92] para com o futuro da humanidade, a partir do qual podemos deduzir todos os demais deveres para com os homens futuros”. Para tal dedução, o juízo é necessário, e para julgar ele utiliza a "ética da solidariedade, da simpatia, da equidade e até mesmo da comiseração" (idem, 2006, p. 93) baseado no imperativo que ele já anunciara e no direito que esses têm de existir no futuro ("o direito de esses homens futuros de existirem" - idem, 2006, p. 93). Além disso, "é preciso considerar o direito e o dever com as suas possibilidades de felicidade" (idem), isso porque, segundo ele, a busca da felicidade é algo normal para os seres humanos (idem, 2006, p. 143).

Na página 56 da mesma obra (2006), Jonas cita Arendt expressamente quando trata da natalidade. As perspectivas, entretanto, são diferentes: a de Jonas é biologista, a dela não, o que o torna mais realista se considerado de um ponto de vista empírico e atual. Nele também há a valorização do "novo" (JONAS, 2006, p. 58). Em Arendt, a natalidade é uma categoria política importante, pois ela traz o novo, e esse pode renovar o mundo, e porta esperança. O "novo" sempre pode encetar eventos inéditos, inesperados, rompendo processos. Em contrapartida, a sociedade possui uma atuação ambígua: ela segue os processos a partir dos regramentos, e o faz sem questionar, e se adapta quando eles forem modificados, mas ao mesmo tempo, possui uma anomia (que Jonas teoriza em 2006, p. 60). Arendt, quanto à essa temática, a teorizou quando tratou da vontade (na obra $A$ vida do espírito, segunda parte - A vontade). A sociedade de massa precisa ser tematizada, pois foi nela que os Sistemas Totalitários puderam se instalar e se desenvolver. Para Jonas (2006, p. 61), é nessa "nova” sociedade que surge a necessidade de uma "nova" ética, diferente da ética anterior.

Hannah Arendt (1906-1975) concebeu a ética como ligada à política, fundamentando-a na liberdade, na pluralidade humana e no juízo. Ela, porém, não pensou uma ética a partir de fundamentos metafísicos, lógicos ou lingüísticos, pois reafirmava continuamente sua preocupação com a política. Jonas também estava ciente do valor da política, a qual, segundo ele (2006, p. 54 e 64), precisa ser observada com cuidado, sem, porém, aprofundar o tema fornecendo os suportes teóricos necessários a uma 
discussão mais consistente. Apesar disso, pode-se afirmar que a melhor forma de governo, para ele, é a direta (cf. idem, 2006, p. 64).

A ética da responsabilidade, em Arendt, não se baseia em normas, sejam de ação, sejam de restrição. Essa ética, então, não é normativa, pois não expõe as regras a serem seguidas, ou os imperativos a serem observados dedutivamente. Também não é uma ética prescritiva, pois não aponta o que deve ser feito ou evitado, isso porque Arendt não pretendia substituir um formalismo por outro, mas "superar qualquer norma moral pré-estabelecida através de uma constante reativação do pensamento" (SCHIO, 2006, p. 225226). O pensar é aquele que mantém o sujeito "conectado" com o seu agir, não lhe permitindo dissociar aquilo que é feito e a busca do significado disso para a sua vida, podendo evitar assim de praticar o "mal banal"10.

Em outros termos, Arendt, ao afastar o utilitarismo ("o mal menor"), o pragmatismo ("meios e fins") e um fundamento transcendente (como Deus, inferno, fim supremo) para a ação humana, ela busca manter unidos o sujeito da ação com sua decisão e sua atitude (cf. ARENDT, 1993, p. 149). Isso porque Arendt prioriza a política, a qual ocorre na esfera pública, sem, entretanto, desvalorizar o nível privado, aquele dos interesses, desejos e preferências do indivíduo. Pois, segundo ela, esse é secundário: quando a comunidade está em questão, ela tem prioridade em relação à vida pessoal e privada do indivíduo. Essa ênfase na preservação da pessoa humana de forma integral, não apenas biológica, do grupo e do ambiente em que vivem os seres do planeta, humanos ou não, é uma preocupação que os dois autores partilham. Em Arendt, então, a ética deve permanecer no horizonte humano para indicar os limites às práticas com resultados perigosos ou duvidosos para a humanidade. É nesse sentido que a ética, em Arendt, versa sobre a responsabilidade pelo mundo ${ }^{11}$.

A ética, diferente da moral, acompanha a política, pois é mais abrangente que os hábitos e comportamentos instituídos por costume e vigentes na sociedade. Ela é a obrigação que cada um tem pelo mundo,

10 A temática do "mal banal" é recorrente e importante na obra arendtiana. Para maiores aprofundamentos, consulte-se, em Arendt, Eichmann em Jerusalém; a introdução ao item "o Pensar" na obra A vida do espírito, em especial; e nos comentadores: Schio (2006, p. 53-73), Souki (Hannah Arendt e a banalidade do mal), Assy (Eichmann, banalidade do mal e pensamento em Hannah Arendt), para citar apenas alguns brasileiros.

${ }^{11}$ Em Schio (2006) esse item é tratado nas p. 225-229. 
entendido como sendo o espaço que abrange o domínio público, ou seja, o espaço do aparecimento do homem aos seus pares, com igualdade, e o ambiente natural com todos os seus integrantes animais, vegetais e minerais imprescindíveis para a continuação da vida. Para ela (1992, p. 203), então, "este nosso mundo, que existiu antes de nós e está destinado a sobreviver aos que nele vivem, simplesmente não se pode dar ao luxo de conferir primariamente sua atenção às vidas individuais e aos interesses a ela associados”. E o homem, por ter se tornado aquele que mais modifica o entorno, precisa responsabilizar-se pelo que fez e faz, preocupando-se com o futuro ${ }^{12}$.

A vida política, ao tratar da comunidade, pressupõe a ética, concebida como sendo a responsabilidade pela permanência do mundo com todas as suas instâncias e, por isso, o suporte para a vida humana, em sentido geral. Esta responsabilidade é individual, pois cabe a cada um refletir sobre os próprios atos e intenções; ela será coletiva enquanto preocupação política, por englobar as questões que são relevantes para todo o grupo humano (existente ou vindouro). Quando políticas, as ações em conjunto precisam ser discutidas com seus argumentos prós e contras, momento que os participantes, os cidadãos preocupados com o mundo, opinam sem coação, com igualdade. Após os esclarecimentos oriundos do diálogo, haveria o momento da deliberação, da decisão, seguindo-se a ação. As atitudes tomadas fariam com que todos se sentissem responsáveis pelo realizado, mesmo que alguma opinião individual não fosse englobada no processo decisório e, consequentemente, na ação.

A reflexão sobre a moralidade, denominada de ética, torna-se imprescindível quando as regras vigentes não mais podem ser utilizadas por prejudicarem algo ou alguém, ou porque contradizem aquilo que historicamente e humanamente se entendia como certo e errado. O exemplo é o Nazismo, no qual o valor da vida foi invertido em efetivação da morte, ocorrendo essa em quantidades antes inimagináveis nos campos de concentração e de extermínio. Neste sentido, quando inexistirem categorias pré-conhecidas para nortear a ação, a faculdade de julgar toma seu assento

\footnotetext{
${ }^{12}$ Assim sendo, confrontando o âmbito público com o domínio privado, o primeiro possui primazia, pois se este for destruído, o mundo privado não possuirá garantias de sobrevivência. Em Kant, a preocupação com as gerações vindouras já constava em seus escritos. No texto intitulado "Resposta à pergunta: que é lluminismo?", A 488 e 489, há exemplos disso.
} 
essencial, e o seu exercício torna-se de capital importância, configurando-se uma questão ética.

Certamente não é fácil pensar e julgar quando tudo parece estar "fora do lugar”, quando não há leis ou regras para seguir, ou que aquelas que existem não devem ser seguidas, porque erradas ou injustas, pois foram outorgadas à revelia da vontade geral, ou ainda quando as regras e leis são ditadas ad hoc por um governante nem sempre legítimo. Quando não há uma normalidade e uma segurança para o ser humano, sua vida e integridade, o pensar, o julgar e o agir são difíceis, porém é nesses momentos que eles se tornam essenciais, tanto para a vida individual quanto para a do grupo humano e seu entorno. É nesses momentos que as capacidades humanas são mais exigidas, e a necessidade de atitudes éticas torna-se mais premente. Este é o momento para avaliar o novo com cuidado, com espontaneidade, pois cada nova ação e cada nova intenção podem levar a consequências que são irreversíveis.

As categorias de pensamento kantiano também se apresentam nas acepções de Arendt, em vários momentos e sentidos. Por exemplo, quando ela afirma que o ser humano precisa ser entendido como fim em si mesmo e jamais como meio para algo, seja útil, lucrativo ou que atenda aos interesses políticos, como no Governo Stalinista, por exemplo. Para que não se perca a dimensão do humano, sob quaisquer que sejam as circunstâncias que se apresentem, ela recorre ao recurso da "mentalidade alargada" de Kant, presente na Crítica da Faculdade de julgar (no parágrafo 40). Esse é um importante "instrumento fictício", pois considera as outras possibilidades de pensar, de entender as questões, ao colocar-se no lugar de outra pessoa, enfim, de pensar a partir de um ponto em que não se está realmente. Nesse momento, a imaginação (como anteriormente mostrado) torna-se um importante instrumento crítico, pois permite a comparação com o pensamento dos outros, assim como com as diversas possibilidades de ação. Em uma sociedade de massa, a imaginação é deslocada do lugar de tornar o ausente presente para a de mera reprodutora de desejos e usada como instrumento para um imaginário que é fornecido pronto.

A verdadeira ética ocorre quando o exercício da faculdade de julgar ocorre, e ao homem é permitido recobrar a sua dignidade de humanizar o mundo. Em outras palavras, os seres humanos tornam o mundo humano pela ação. A ação humana, quando espontânea, devido à capacidade humana de iniciar processos novos, constitui um espaço comum de convívio e de 
discussão. Sem este espaço ocorre a perda da possibilidade, e também da capacidade, de pertencimento e de participação no espaço em conjunto com os outros seres humanos, denominados por ela de "pluralidade" e pertencente à condição humana. Inexistindo o espírito público, advém o sentimento de desolação e de inutilidade, não havendo humanização, mas a perda do humano (cf. SCHIO, 2006, p. 217-224).

\begin{abstract}
A ética está ligada ao julgamento em seu exercício mais autônomo, enquanto faculdade do espírito. Ou seja, quando inexiste uma regra geral, ou esta não é mais suficiente para compreender um particular, e a orientação para o agir é escassa, a faculdade de julgar precisa exercer a sua tarefa de forma autêntica e, portanto mais relevante. Em tais momentos, o juízo é imprescindível, pois tratará com as questões mais fundamentais da vida humana, isto é, dos princípios primeiros. Os princípios fundamentais são a vida, a dignidade humana e a sobrevivência de suas comunidades inseridas em seu contexto amplo, o planeta, com o meio ambiente e seus habitantes vivendo com integridade. Dessa forma busca-se as possibilidades para o agir mais adequado à situação particular.
\end{abstract}

Nesta perspectiva, às pessoas cabe a tarefa de "produzir e preservar o mundo para o constante influxo de recém-chegados que vêm a este mundo na qualidade de estranhos, além de prevê-los e levá-los em conta”, afirma Arendt (1991, p. 17). A ética, portanto, relaciona-se à responsabilidade pelo mundo, ligada à pluralidade, à natalidade, ao espaço político. Em outros termos, segundo a autora, "as coisas que devem sua existência exclusivamente aos homens também condicionam os seus autores humanos" (idem, 1991, p. 17). Arendt, nesse momento, pensa em tudo aquilo que o homem tem a capacidade de fazer, o que engloba a tecnologia, ou pode deixar de fazer, como degradar o meio ambiente. Nesta perspectiva, tudo o que poderia não existir, mas que existe, sendo por obra humana, torna o seu autor responsável, assim como tudo o que deveria ser feito, e não o é. E isto se estende aos autores no plural, a 
nenhum eximindo da sua participação ou mesmo da omissão, o que apenas é possível por meio da vivência política ${ }^{13}$.

Arendt aspira entrelaçar a ética e a política através de uma ética da responsabilidade pelo mundo. Desta forma, afasta-se o ensejo por uma ética que atue apenas superficialmente, como aquelas generalizadoras, baseadas no "deve", no "tem-se", e que acabam por cair em um "vazio", tanto de compreensão quanto de ação. Não há ética sem autor, e quando esses são desconhecidos, não há responsabilização, sequer "ética". Na ausência de parâmetros para embasar o agir, e mesmo havendo uma moral absoluta, que valha para todos indistintamente e sem adesão pessoal, o julgar precisa ser ativado junto ao pensar. A questão ética refere-se aos indivíduos tratados particularmente, mesmo que eles tenham agido em um grupo, e por isso, desprovidos de intenções explícitas. Em outras palavras: o indivíduo, quanto à eticidade, não pode tentar desculpabilizar-se por executar algo em companhia dos outros. Ou ainda, por ter-se tornado passivo em situações que exigiam posicionamentos refletidos, pois a atitude ética exige opções que escapam à simples obediência às ordens ou às regras. Nesta perspectiva, "a questão urgente colocada pelo fenômeno da culpabilidade coletiva é aquela da exigência de preservar a possibilidade de julgar qualquer um sobre seus atos", entende Roviello (1987, p. 52) ${ }^{14}$. A afirmação de ter somente "cumprido ordens" - como o fizera Eichmann, no Tribunal em Jerusalém não pode desresponsabilizar o agente pelos atos praticados. Se assim fosse, não haveria como imputar qualquer culpa a alguém: sempre haveria uma causa oculta, na infância, no inconsciente, na necessidade de ser aceito no grupo, por exemplo, e que justificaria as ações, desculpando seu agente.

Enquanto emissor ou não de comandos, o ser humano não pode deixar de lado as suas características propriamente humanas de ser autônomo, de comandar-se, mesmo se o comando seja pela não-obediência à ordem, e a consequência disso, a punição, mesmo que injusta. Como apregoou Kant ${ }^{15}$, cada ser humano precisa “ousar” utilizar o próprio

\footnotetext{
${ }^{13}$ A influência kantiana, extraída da Fundamentação Metafísica dos Costumes, Terceira Seção, na qual Kant fundamenta a moralidade na liberdade e na vontade autônoma, faz-se sentir nestas concepções aredtianas. Kant, por exemplo, escreveu: "A todo ser racional que tem uma vontade temos que atribuirIhe necessariamente também a idéia de liberdade, sob a qual ele unicamente pode agir" (BA 101).

14 "La question urgente posée par le phénomène de la culpabilité organisée est celle de l'exigence de préserver la possibilité de juger quelqu'un sur ses actes." (grifo da autora).

${ }^{15} \mathrm{Na}$ obra "Resposta à pergunta: que é lluminismo?", A 481-2.
} 
entendimento, pensar e decidir por si. Nesse sentido, Arendt não é puramente kantiana, pois ela, além de valorizar a razão humana, não a deixa só na tarefa de pensar, julgar e agir: os sentimentos, como a amizade, são valorizados na busca de um consenso sem coerção. A sensibilidade também é importante para que o ser humano se envolva como um ser completo. Por exemplo, a cultura pode tornar o cidadão mais apto para julgar, para entrar em contato com os outros e pensar, decidir e agir.

A ética, neste sentido, afirma a necessidade de preservar o espaço da humanidade, espaço que é político, o qual permite a discussão sobre o mundo, na busca de compreensão sobre ele e sobre os seus fatos, novos ou não. É preciso, então, que cada ser humano não se "feche" dentro de si próprio ou de seu trabalho, de suas necessidades ou preferências. Desta forma, a ética, exposta por Arendt, é uma ética positiva, e também realista, por exigir que os cidadãos sejam constantemente sujeitos de seus atos, que exercitem ininterruptamente as suas faculdades espirituais - pensamento, volição e julgamento - que se tornam visíveis através de suas ações.

Arendt e Jonas tematizaram a ética, a vida e a ação dos seres humanos no mundo, que envolve a natureza, suas relações recíprocas, o tempo, entre outras questões relevantes. A ética, para ambos, porta os termos "responsabilidade" e "futuro", porém elas contêm diferenças que as tornam, de certa forma, complementares. Cada uma enfoca e permite reflexões em direções que se tocam ou perpassam, iluminando regiões reflexivas diferentes. As reflexões de Arendt, tão teóricas quanto as de Jonas, parecem mais realizáveis porque enfocam a política e as possibilidades de ações entre os seres humanos que têm o mundo em comum e o dever de preservá-lo para as gerações vindouras. Jonas buscou uma fundamentação no "ser", Arendt na política e no julgar.

Não se pode esquecer que eles se conheciam, eram amigos, conversavam, e que, certamente receberam influências um do outro. Em especial, sabe-se que Jonas havia lido as obras de Arendt, e muitas vezes aborda as mesmas problemáticas, mas sem a citar. Porém, ele conhecia tanto o pensamento da autora, quanto os temas por ela tratados. No enterro de Arendt, ele fez um discurso no qual demonstrou conhecer em profundidade o pensamento arendtiano, assim como as críticas que esse sofreu e ainda recebia, como as suas próprias a ela dirigidas. Jonas foi mais longevo que Arendt. Assim ele pode desenvolver mais suas concepções, repensá-las, reelaborá-las, inclusive aproveitando os desdobramentos que o pensamento 
de Arendt recebeu após a morte dela. Em síntese, o pensamento de Jonas tem "luz própria", pois ele foi kantiano ao ponto de pensar por si mesmo, e de forma consequente. Se as suas ideias não são aceitas, ou recebem críticas, é porque elas têm fecundidade. $O$ pensamento de Arendt também sofre críticas. Apesar disso, sua importância não pára de crescer. E isso está conforme o pensamento de ambos, em especial no de Arendt, em que a conversa, como a que ocorre entre os amigos, é sempre profícua porque cria laços, porque permite o entendimento, e desse o surgimento do significado, imprescindível para uma vida humana autêntica. 


\section{Referências}

ARENDT, H. A condição humana. $5^{\mathrm{a}}$ ed. rev. Rio de Janeiro: Forense Universitária, 1991.

. A vida do espírito: o pensar, o querer, o julgar. Rio de Janeiro: RelumeDumará/UFRJ, 1991a;

. Eichmann à Jerusalém: rapport sur la banalité du mal. Paris: Gallimard, 1991b;

. Entre o passado e o futuro. São Paulo: Nova Perspectiva, 1992.

. A dignidade da política. Rio de Janeiro: Relume-Dumará, 1993.

Lições sobre a filosofia política de Kant. Trad. de André Duarte de Macedo. Rio de Janeiro: Relume-Dumará, 1993a.

. Compreender - formação, exílio e totalitarismo (ensaios). São Paulo: Cia das Letras/Belo Horizonte: EdUFMG, 2008.

ASSY, B. "Eichmann, banalidade do mal e pensamento em Hannah Arendt". In: MORAES, E. J. de. \& BIGNOTTO, N. (org.). Hannah Arendt. diálogos, reflexões, memórias. Belo Horizonte: EdUFMG, 2001.

JONAS, H. O princípio responsabilidade - ensaio de uma ética para a civilização tecnológica. Rio de Janeiro: Contraponto/EdPUC-Rio, 2006.

Évolution et liberte. Paris: Payot et Rivages, 2005.

"O fardo e a benção da mortalidade". In: Princípios - Revista de Filosofia.

Trad. de Wendell Evangelista Soares Lopes. Natal, v. 16, n. 25, jan-jun/2009, p. 265281.

KANT, I. "Resposta à pergunta: que é Iluminismo?". In: A paz perpétua e outros opúsculos. Trad. de Artur Morão. Lisboa: Edições 70, 1988, p. 11-19.

. Fundamentação da metafísica dos costumes. Trad. de Paulo Quintela. Lisboa: Edições 70, 1991.

. A religião nos limites da simples razão. Lisboa: Edições 70, 1992.

. Crítica da faculdade do juízo. Trad. de Valério Rohden e António Marques.

Rio de Janeiro: Forense Universitária, 1993.

RODRÍGUEZ, A. R. "Naturaleza Orgânica y Responsabilidad Ética: Hans Jonas y sus críticos”. In: Trans/Form/Ação: Revista de Filosofia/Universidade Estadual Paulista, São Paulo, 27(2), 2004, p. 97-111.

ROVIELLO, A.-M. Sens commun et modernité chez Hannah Arendt. Bruxelles: Éditions Ousia, 1987. 
SANTOS, R. dos. "Hans Jonas". MÜHL, Eldon H. et al. Textos preferenciais para a educação em direitos humanos. Passo Fundo: IFIBE, 2009, p. 77-82.

SCHIO, S. M. Hannah Arendt. história e liberdade (da ação à reflexão). Caxias do Sul: EDUCS, 2006.

SOUKI, N. Hannah Arendt e a banalidade do mal. Belo Horizonte: EdUFMG, 1998.

Email: soniaschio@hotmail.com

Recebido em: Setembro/2010

Aprovado em: Dezembro/2010 